\title{
Comparing the Efficacy of Oral Sucrose and Acetaminophen in Pain Relief for Ophthalmologic Screening of Retinopathy of Prematurity
}

\author{
Fatemeh Seifi ${ }^{1}$, Ali Peirovifar ${ }^{2}$, Manizheh Mostafa Gharehbaghi ${ }^{3, *}$ \\ ${ }^{1}$ Department of pediatrics, Tabriz University of Medical Sciences, Tabriz, Iran \\ ${ }^{2}$ Depatrtment of Anesthesiology, Tabriz University of Medical Sciences, Tabriz, Iran \\ ${ }^{3}$ Pediatric Health Research Center, Department of pediatrics, Tabriz University of Medical Sciences, Tabriz, Iran \\ *Corresponding author: gharehbaghimm@yahoo.com
}

Received March 12, 2013; Revised April 09, 2013; Accepted April 11, 2013

\begin{abstract}
Retinopathy of prematurity (ROP) is a potential cause for visual impairment in preterm newborn infants with gestation age 32 weeks or less and birth weight less than 1500 gram. There are several studies that reported physiologic and behavioral responses to painful and stressing screening examination. This study was conducted to compare the efficacy of sucrose and acetaminophen in pain control during eye examination in premature infants. A prospective randomized clinical trial was carried out in a tertiary level NICU. One hundred twenty preterm infants were randomly allocated in to 3 groups. Group A received oral acetaminophen $15 \mathrm{mg} / \mathrm{kg} 30$ minutes before eye examination and $0.2 \mathrm{ml}$ sterile water, given by mouth using a syringe, during examination; group B $0.2 \mathrm{ml}$ sucrose $25 \%$ and group $\mathrm{C} 0.2 \mathrm{ml}$ sterile water given by mouth using a syringe during examination. Ophthalmologic examinations were recorded by videotape. Pain score was determined by using PIPP during first 45 seconds and at last 45 seconds of eye examination. There was no significant difference between groups regarding gestation age, birth weight and age at examination. The mean PIPP score at first $45 \mathrm{sec}$ were $12.9 \pm 2.4,9 \pm 2.1$ and $13.7 \pm 1.6$ for groups $\mathrm{A}, \mathrm{B}$, and $\mathrm{C}$ respectively ( $\mathrm{p}<0.001)$. It was $12.3 \pm 2.4,11.2 \pm 3$ and $12.1 \pm 2.6$ at last $45 \mathrm{sec}$ of examination in groups $\mathrm{A}, \mathrm{B}$, and $\mathrm{C}$ respectively $\mathrm{P}=0.12$.Two patients had apnea during first 12 hours after examination and both of them were in group C. In our study, using sucrose was associated with reduced pain score in neonates undergoing screening for ROP at beginning of eye examination but not at the last seconds of examination.
\end{abstract}

Keywords: retinopathy of prematurity, pain, preterm neonates, PIPP

\section{Introduction}

Retinopathy of prematurity (ROP) is a potential cause for visual impairment in preterm newborn infants with gestation age 32 weeks or less and birth weight less than $1500 \mathrm{~g}$. Early detection and treatment of developing ROP have been shown to be effective in prevention of blindness [1]. Screening of ROP with a serial indirect ophthalmologic examination until the infant became low risk for this disease is essential. There are several studies that reported physiologic and behavioral responses or adverse reactions to painful stressing screening examination [2-7]. Repeated exposure to pain in preterm infants may have long term consequences on the neurological and behavioral development [8,9]. Pain assessment is basic for its management [10]. Inability of neonates to verbalization makes this pain assessment and management subjective. Pain assessment is usually based on physiologic and behavioral factors. There are several validated and reliable pain scoring systems [11]. The premature infant pain profile (PIPP) is a behavioral measure of pain for premature infants that developed at theToronto and McGill universities in Canada [12].
Several strategies, including pharmacologic and non pharmacologic methods, have been used for prevention of pain during procedures. Sucrose is one of the most commonly used non-pharmacologic interventions for pain control in infants $[13,14,15]$. Analgesic effect of sucrose is thought to be mediated by stimulation lingual sweet taste receptors and release of endogenous opioids. Paracetamol ( $\mathrm{N}$-acetyl-P-aminophenol) is an antipyretic and analgesic agent that is less potent than opioids with fewer side effects. It acts by inhibiting the cyclooxygenase(COX) enzymes in the brain and it is useful for mild to moderate pain in infants and neonates which can administered by oral, rectal or intravenous route [16,17]. The absorption half life for oral elixir preparation is $0.21 \mathrm{~h}$ with a lag time of $0.42 \mathrm{~h}$ that is further delayed in premature neonates $(2 \mathrm{~h})$ in first few days of life [18].

Since there is not a universal strategy for pain reduction during eye examinations, this study was conducted to compare the efficacy of oral sucrose and acetaminophen for pain reduction in ROP screening eye examinations.

\section{Materials and Methods}


A randomized controlled clinical trial was carried out in a tertiary level neonatal intensive care unit (Al Zahra Hospital, Tabriz, Iran) from October 2011 to October 2012. One hundred twenty two preterm infants, gestational age less than 32 weeks, were enrolled in this study. Ethic committee of Tabriz University of Medical Sciences approved the study. Written informed consent was obtained from the parents. Infants receiving mechanical ventilation at time of ROP screening or receiving sedatives or narcotics, infants with severe birth asphyxia (APGAR score $\leq 3$ at 5 minutes) and neonates with major congenital anomalies were excluded from this study. Neonates were allocated in three groups with a computer based randomization process according to their ophthalmologic examination sequence and by sealed opaque envelops. Infants were enrolled only once in this study. Mydriatics used before eye examination were homatropine $2 \%$ and phenylepherine $2.5 \%$ one drop in each eye and repeated 5 minute later. Infants received topical tetracain $1 \%$ just prior to eye examination. Eye examinations were carried out following adequate pupillary dilatation (30 minutes after mydriatic drops) by same experienced ophthalmologist. Acetaminophen was administered to infants in group A orally $15 \mathrm{mg} / \mathrm{kg} 30$ minutes before examination and $0.2 \mathrm{ml}$ sterile water during initiation of eye examination to achieve blindness at assessing. Patients in group B received $0.2 \mathrm{ml}$ sucrose $24 \%$ solution by mouth using a syringe during the initiation of eye examination. Sterile water $0.2 \mathrm{ml}$ was given as placebo to neonates in group C. No pacifier was used and oral drugs were given by mouth using a syringe in all studied neonates. ROP screening examinations were recorded by videotape. Physiologic parameters including heart rate, respiratory rate and base line $\mathrm{SpO}_{2}$ were determined in all patients prior to eye examination and during examination and every 5 minutes until 20 minutes after examination using pulse oxymeter and a nurse who was blind to the study groups. Two neonatologists experienced in the use of PIPP scoring and blind to the intervention groups determined pain score by 30-sec observation of neonates' responses in videotape at starting eye examination and during last 45 seconds of eye examination. Data were analyzed using the Statistical Package for Social Science Software(SPSS)version 16.0. Variables were expressed in percentages and mean \pm standard deviation. Data were analyzed with Chi -square test and one way analysis of variance (ANOVA).The difference was considered significant for $p$. value less than 0.05 .

\section{Results}

One hundred twenty two infants who underwent ROP screening eye examination were included in this study. One neonate in group $\mathrm{C}$ and one infant in group B were excluded because of impaired video tape recording and covering of neonates' face with examiner's hand that makes pain assessing impossible. Sixty four infants (53\%) were male. The mean gestation age of studied infants was $27.6 \pm 2$ weeks and their birth weight was $986 \pm 249$ gr. APGAR score at 1 minute and 5 minute were $5.3 \pm 2$ and $7.4 \pm 1.6$ respectively. The mean age of neonates at study was $39 \pm 11.7$ days and their weight was $1238 \pm 316 \mathrm{gr}$. There was no significant difference between groups regarding gestation age, birth weight and age at examination (Table 1).

There was history of assisted ventilation in 20 (48.8\%), $16(40 \%)$ and $11(28.2 \%)$ of patients in groups A, B and C respectively $(\mathrm{p}=0.22)$. surfactant replacement therapy was done in $29(70.7 \%), 26(65 \%)$ and $25(64.1 \%)$ neonates in groups $\mathrm{A}, \mathrm{B}$ and $\mathrm{C}$ respectively $\mathrm{p}=0.91$. The mean PIPP scores in three groups are showed in Table 2. The duration of examination was 2-3 minutes in all neonates. Two patients had apnea during first 12 hours after examination and both of them were in group $\mathrm{C}$.

Table 1. Characteristics of neonates in 3 groups

\begin{tabular}{|c|c|c|c|c|}
\hline & $\begin{array}{c}\text { Group A } \\
(\mathrm{n}=41)\end{array}$ & $\begin{array}{c}\text { Group B } \\
(n=40)\end{array}$ & $\begin{array}{c}\text { Group C } \\
(n=39)\end{array}$ & $\begin{array}{c}\mathrm{P} \\
\text { value } \\
\end{array}$ \\
\hline $\begin{array}{l}\text { Gender, } \\
\text { male n }(\%)\end{array}$ & $21(51.2)$ & $21(52.5)$ & $22(56.4)$ & 0.89 \\
\hline $\begin{array}{c}\text { Labor, C/S } \\
\text { n }(\%)\end{array}$ & $13(31.7)$ & $13(32.5)$ & $20(51.3)$ & 0.12 \\
\hline $\begin{array}{c}\text { Birth } \\
\text { weight, gr* }\end{array}$ & $921.5 \pm 220.6$ & $1028.5 \pm 258.1$ & $1013.7 \pm 260.5$ & 0.11 \\
\hline $\begin{array}{l}\text { Gestation } \\
\text { age, wk* }\end{array}$ & $27.4 \pm 1.9$ & $27.9 \pm 1.9$ & $27.4 \pm 2.2$ & 0.53 \\
\hline \multicolumn{5}{|l|}{ Apgar score } \\
\hline 1 minute* & $5.2 \pm 2.4$ & $5.3 \pm 2.2$ & $5.5 \pm 2.2$ & 0.84 \\
\hline 5 minute* & $7.3 \pm 1.7$ & $7.3 \pm 1.6$ & $7.6 \pm 1.4$ & 0.70 \\
\hline \multicolumn{5}{|c|}{ Antenatal corticosteroid, $\mathrm{n}(\%)$} \\
\hline 2 doses & $21(51.2)$ & $20(50)$ & $15(38.5)$ & 0.59 \\
\hline One dose & $15(36.6)$ & $14(35)$ & $20(51.3)$ & \\
\hline no & $5(12.1)$ & $6(15)$ & $4(10.2)$ & \\
\hline
\end{tabular}

Note: Group A: Acetaminophen $15 \mathrm{mg} / \mathrm{kg}$

Group B: Sucrose $0.2 \mathrm{ml}$

Group C: sterile water $0.2 \mathrm{ml}$

* Mean \pm Standard Deviation

$\mathrm{C} / \mathrm{S}$ : Cesarean section

Table 2. Pain assessment in studied groups

Table 2. Pain assessment in studied groups
\begin{tabular}{|c|c|c|c|c|}
\hline & $\begin{array}{c}\text { Group A } \\
(\mathrm{n}=41)\end{array}$ & $\begin{array}{c}\text { Group B } \\
(\mathrm{n}=40)\end{array}$ & $\begin{array}{c}\text { Group C } \\
(\mathrm{n}=39)\end{array}$ & \multirow{2}{*}{ P.Value } \\
\hline $\mathrm{PIPP}_{1}$ score & $12.9 \pm 2.4$ & $9 \pm 2.1$ & $13.7 \pm 1.6$ & $<0.001$ \\
\hline $\mathrm{PIPP}_{2}$ score & $12.3 \pm 2.4$ & $11.2 \pm 3$ & $12.1 \pm 2.6$ & 0.12 \\
\hline Number of eye examination \\
\hline First & $23(56.1)$ & $21(52.5)$ & $26(66.6)$ & \multirow{2}{*}{0.45} \\
\hline Second & $18(43.9)$ & $19(47.5)$ & $13(33.3)$ & \\
\hline
\end{tabular}

PIPP1 PIPP score in first 45 seconds of examination

PIPP2 PIPP score in last 45 seconds of examination

\section{Discussion}

Patients that received sucrose had significantly lower PIPP score compared with acetaminophen or sterile water treated groups at the beginning of eye examination but not at its termination. These findings indicate that sucrose does not abolish pain responses during ROP examination in preterm infants. There are several studies comparing different doses and routes of sucrose administration with sterile water. Sullivan and coworkers [19] assessed sucrose and sterile water combined with non nutritive sucking and swaddling in total 40 infants undergoing primary eye examination. They used neonatal pain agitation and sedation scores (N-PASS) and found fewer infants with episodes of desaturation or bradycardia in sucrose group. They concluded that pain scores remained consistently high and appropriate pain relief for ROP remains a challenge. Gal studied 23 infants and showed short term reduced pain score in sucrose group immediately after examination [20]. The optimal dose of sucrose in pain control is not determined. The reported doses differ from $0.05-0.5 \mathrm{ml}$ of sucrose $24 \%(0.012$ - 
$0.12 \mathrm{~g})$ to $2 \mathrm{ml}(0.48 \mathrm{~g})$ sucrose. In a study of 32 infant, efficacy of sucrose was compared with sterile water. Both groups demonstrated significant pain score (14 \pm 3 ) in response to eye examination during insertion of a lid speculum and depression of the sclera [21]. Their studied infants don't benefit from high dose $(0.48 \mathrm{~g})$ sucrose. They used the solution 2 minutes prior onset of eye examination but we used sucrose simultaneously with eye examination. PIPP score in our study is very close to Mitchell results that used local anesthetic eye drops as part of the routine eye examination procedure and three doses of sucrose $24 \%$ at 2 minutes intervals before and during eye examination [22]. A recent Cochrane review showed that single doses of oral sucrose reduce crying, facial grimacing and motor activity in term and preterm infants during minor painful procedures [23]. The effects of repeated doses of sucrose have examined in a few studies $[24,25,26,27]$. In one study, preterm infants with greater exposure to sucrose (>10doses in 24 hours) had poorer motor and attention development at ages 36 and 40 weeks [24]. A very low incidence of short term adverse events including hyperglycemia, oral infections, necrotizing enterocolitis, intra-ventricular hemorrhage and death reported [24,25,26,27]. In agreement with previous studies [28], the pain score was not reduced in patients treated with acetaminophen. Acetaminophen is useful for mild to moderate pain and is not helpful for painful eye examination. We have not any superiority of this pharmacologic pain control over non pharmacologic methods and acetaminophen use is not recommended routinely before eye examination.

\section{Conclusion}

In our study, using sucrose was associated with reduced pain score in neonates undergoing screening for ROP at beginning of eye examination but not at the last seconds of examination.

This result demonstrates that sucrose is relatively effective for reducing pain during eye examination that is believed to be more painful than heel sticks. It is suggested that repeated doses or higher volume of sucrose may be more effective than single dose. We have not used repeated doses of sucrose and pain score was higher at the termination of eye examination. It is recommended future studies with large number of patients and using higher volume of sucrose or repeated doses during eye examination to determine the optimum dose of sucrose for pain control during this painful procedure.

\section{Acknowledgments}

The authors would like to thank research vice chancellor of Tabriz University of Medical Sciences and children's Health Research Centre for providing the funding for the study. We thank Dr Eftekhari Milani AA, Mrs Sabuhi R, Mrs Nikzad H and Mrs Karamooz M for their assistance in research performance. We also gratefully acknowledge the work done by the staff at the neonatal intensive care unit and neonatal unit, Al-Zahra hospital, Tabriz, Iran.

\section{References}

[1] Wheathey CM, Dickinson JL, Mackey DA, Craig JE, Sale MM. Retinopathy of prematurity: recent advances in our understanding. Br J Ophthalmol. 2002; 86(6):696-700.

[2] Porter FL, Lueder G. Anesthetized retinopathy of prematurity examinations elicit significant physical instabilityin premature infants. Pediatr Res 1997; 41 (4):170-170.

[3] Rush R, Rush S, Nicolau J, Chapman K, Naqui M. Systematic manifestations in response to mydriasis and physical examination during screening for retinopathy of prematurity. Retina 2004; 24(2):242-245.

[4] Mehta M, Adams GGW, Bunce C, XingW, Hill M. Pilot study of systematic effects of three different screening methods used for retinopathy of prematurity. Early Dev 2005; 81(4):355-360.

[5] Craig KD, Whitfield MF, Grunau RV, Linton J, Hadjistavropoulos HD. Pain in the pre term neonates:behavioral and physiologic indices. Pain 1993; 52 (3):287-299.

[6] Nair AK, Pai MG, da Costa DE, Khusaiby SM. Necrotizing enterocolitis following ophthalmologic examination in preterm neonates. Indian Pediatr 2000; 37 (4):417-421.

[7] Bonthala S, Sparcks JW, Musgrove KH, Berseth CL. Mydriaticsslows gastric emptying in preterm infants. J Pediatr 2000; 137(3):327-330.

[8] Bhutta AT, Anand KJS.Vulnerarability of the developing brain:neuronal mechanisms. ClinPerinatol 2002; 29 (3):357-372.

[9] Grunau R. Early pain in preterm infants: a model of long term effects. ClinPerinatol. 2002; 29 (3):373-394.

[10] Samra HA, Mc Grath JM.Pain management during retinopathy of prematurity eye examinations.A systematic review. Adv Neonatal Care 2009; 9 (3):99-110.

[11] Abu-Saad HH, Bours GJJW, Stevens B, Hamers JPH. Assessment of pain in the neonate:.SeminPerinatol 1998; 22 (5):402-416.

[12] Stevens BJ, Johnstone CC. Physiological responses of premature infants to a painful stimulus.Nurs Res 1994; 43 (40):226-231.

[13] Leslie A, Marlow N. Non pharmacological pain relief.Semin Fetal Neonatal Med. 2006; 11(4):246-250.

[14] Slarter R, CornelissenL,FabriziL,Patten D, Yoxen J, Worley A, et al. Oral sucrose as an analgesic drug for procedural pain in newborn infantsa randomized controlled trial. Lancet 2010; 379 (9748): 1225-1232.

[15] Pinelli J, Symington AJ. Non nutritive sucking for promoting physiologic stability and nutrition in pre term infants. Cochrane Database Sys Rev.2005; 4. Art. No.:CD001071.

[16] Alegaert K, Van der Marel CD, Debeer A, PluimMAL, VanLingen RA, Vanhole C, et al. Pharmacokinetics of single dose intravenous propacetamol in neonates: effect of gestational age. Arch Dis Child Fetal Neonatal Ed 2004; 89:F25-F28.

[17] Hall RW, ShbarouRM .Drugs of choice for sedation and analgesia in NICU.ClinPerinatol 2009; 36 (1):15-26.

[18] Anderson BJ, Van LingenR,Tom H, Yuan-Chi L, Nicholas H.Acetaminophen developmental pharmacokinetics in premature neonates and infants:a pooled population analysis. Anesthsiol 2002; 96(6)1336-1345.

[19] O'Sulivan A, O'Connor M, Brosnahan D, Mc Creery K, Dempsey EM. Sweeten soother and swaddle for retinopathy of prematurity screening: a randomized placebo controlled trial. Arch Dis Child Fetal Neonatal Ed 2010; 95(6): F419-F422.

[20] Gal P, Kissling GE, Young WO, .efficacy of sucrose to reduce pain in premature infants during eye examination for retinopathy of prematurity. Ann Pharmacother 2005; 39:1029-1033.

[21] Grabska J, Walden P, LererT, Kelly C, Hussain N, Donovan T, et al. can oral sucrose reduces the pain and distress associated with screening for retinopathy of prematurity? J Perinatol 2005; 25:3335.

[22] Mitchell A, Stevens B, Mungan N, Johnson W, Lobert S, Boss B. Analgesic effects ofsucrose and pacifier during eye examinations for retinopathy of prematurity. Pain Management Nursing 2004; 5(4):160-168.

[23] Stevens B, Yamada J, Ohlsson A. Sucrose for analgesia in newborn infants undergoing painful procedures. Cochrane Database Syst Rev 2010; 1. Art. No.:CD001069.

[24] Johnson CC, Filion F, Snider L, et al. Routine sucrose analgesia during the first week of life in neonates younger than 31 weeks' post conceptional age. Pediatrics 2002; 5(4):160-168.

[25] Stevens B, Yamada J, Beyene J,et al. Consistent management of repeated prodeural pain with sucrose in preterm neonates: is it 
effective and safe for repeated use over time? Clin J pain 2005; 21(6):543-548

[26] Taddio A, Shah V, Atenafu E, Katz J.Influence of repeated painful procedures and sucrose analgesia on the development of hyperalgesia in newborn infants. Pain 2009; 144 (1-2):43-48.

[27] Caspardo CM, Miyae CI, Chimello JT, Martinez FE, MartusLinhares MS. Is pain relief equally efficacious and free of side effects with repeated doses of oral sucrose in preterm neonates? Pain 2008; 137(1):16-25.

[28] Shah V, Taddio A, Ohlsson A. Randomized controlled trial of paracetamol for heel prick pain in neonates. Arch Dis Child Fetal Neonatal Ed.1998; 79: F209-F21. 